\title{
Mediating medical negligence claims
}

\author{
by Linda Mulcahy
}

\begin{abstract}
Linda Mulcahy of the University of London summarises a recently-published report on the Department of Health's Medical Negligence Mediation Pilot Scheme.
\end{abstract}

\begin{abstract}
$1 \mathrm{n}$ important research report published in January 2000 presents the findings of the official evaluation of the Department of Health's Medical Negligence Mediation Pilot Scheme. The scheme was launched in April 1995 as a response to the criticisms being made of the way claims were being managed and the increasing incidence of medical negligence actions. The research team found that claimants with experience of traditional claims management felt that health authorities, trusts and solicitors were overly defensive in their responses to claimants. They also found it difficult to get information from hospitals, and greater openness and more frequent meetings were the top two improvements they wanted to see in the existing system. Claimants felt that traditional claims management left them unable to put their grievance behind them and that many of their questions remained unanswered.
\end{abstract}

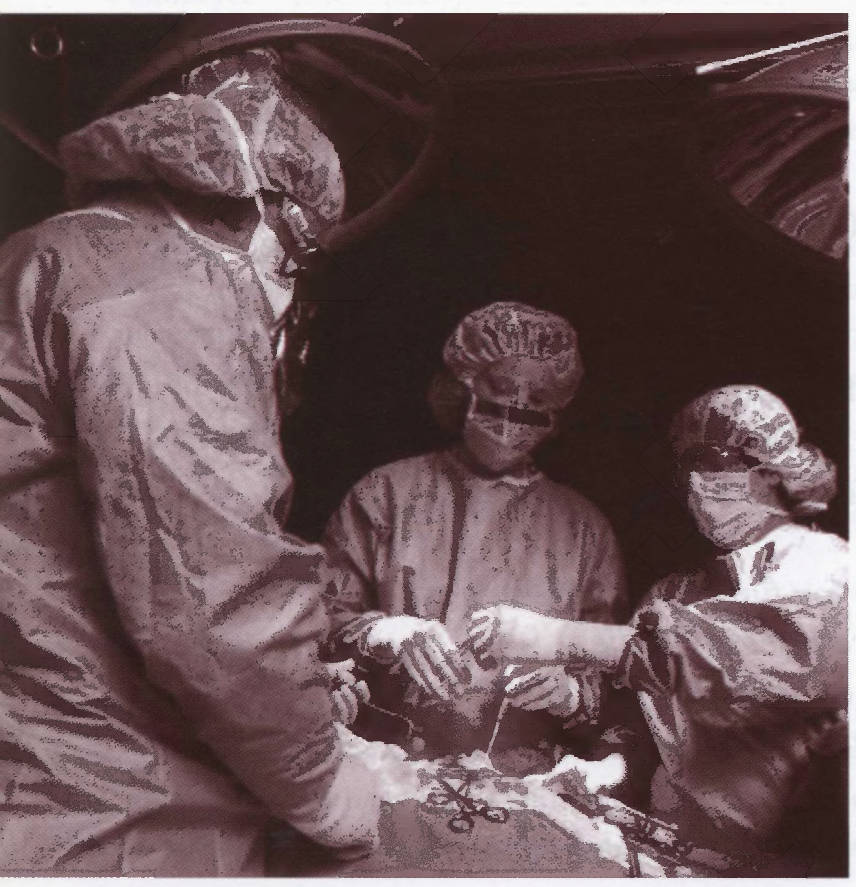

\section{PILOT SCHEME RESULTS}

The pilot scheme sought to test whether mediation could improve satisfaction with claims management. It was anticipated that up to 40 cases would be mediated over a three-year period but by the end of the pilot only 12 cases had been dealt with. Most cases were mediated after the issue of a writ, and expert evidence had been obtained by both parties in the majority of cases. All the defendants and 10 of the claimants were represented by solicitors at the mediation. The cases involved a variety of medical specialities and took an average of seven hours to settle through mediation. Settlement was reached in 11 of the cases, the average settlement being just over $£ 34,000$. In addition to compensation, a number of additional remedies not normally associated with legal settlement were granted. These included apologies, in-depth explanations of medical decisions, new treatment plans and information about the location of a foetus' place of burial.

\section{PROBLEMS}

Four main problems with the scheme were identified. Firstly, the policy environment was perceived to be unsupportive of the scheme. The Legal Aid Board was not prepared to fund mediation until the final year of the pilot scheme and concerns were expressed by a number of expert solicitors that the NHS Litigation Authority was not supportive of the initiative and discouraged referrals. Secondly, there were indications that mediated settlement could prove to be most costly when compared with similar cases managed in more traditional ways. Thirdly, doctors were almost unanimously opposed to the scheme, which they felt exposed them in ways which negotiated settlement between solicitors did not. Finally, expert solicitors were reluctant to refer cases. Despite seeing the development of mediation as inevitable after the Woolf reforms of civil litigation, solicitors felt ill-equipped to 
adopt more conciliatory approaches to dispute settlement and were not prepared to recommend mediation to their clients. Their reluctance to participate in the scheme can largely be explained by their lack of training and a feeling amongst one group of expert solicitors interviewed that good solicitors can settle a case without the help of a mediator. Unfortunately, as Lord Woolf's analysis of civil litigation and the data collected for this report have shown, this is not always the case.

\section{SUCCESSES}

Despite these negative aspects of the evaluation a number of successes of the pilot scheme were also identified. Of all those who participated, claimants appeared to achieve the most. In particular they valued the opportunity mediation gave them to put their point of view, have their questions answered by the 'medic' involved and participate actively in the settlement process. Many claims managers were also complimentary about the scheme. They welcomed the chance mediation gave them to provide a more satisfactory outcome for claimants and felt that mediation could achieve a much speedier and more private settlement than might normally be the case. Solicitors who represented the parties at mediation had mixed feelings about the scheme, but recognised that mediation concentrated their efforts on a case and encouraged settlement to be led by the parties rather than the court timetable.

\section{CONCLUSION}

The evaluation of the mediation pilot scheme suggests that mediation has considerable potential. However, a number of issues have been left unresolved. There has been insufficient discussion of the place for medical personnel in mediation. What level of accountability can we expect from doctors in the management of medical negligence claims? It seems wrong that not all the doctors involved in the cases evaluated were invited to, or even informed about, the mediation of a claim against them. It seems equally inappropriate that some doctors refused to give an account of their activity to those who claimed they had been damaged by them.

The report also raises the question of whether it is appropriate for solicitors to act as gatekeepers to mediation of medical negligence mediation. Whilst many may be opposed to mediation on principled grounds is it nonetheless not the case that the possibility of mediating their claim should be put to clients in a measured way?

Finally, the report raises the question of whether a more integrated approach to dispute resolution in the NHS is called for. Mediation is just one of a number of approaches to dispute resolution which could be employed in the NHS. Yet the debate about mediation has been conducted in isolation from discussion of conciliation of clinical complaints.

Perhaps the time has come for the Department of Health to consider a joined-up approach to dispute resolution for those who call the NHS to account?

\section{Linda Mulcahy}

Reader in Law, Birkbeck College, University of London

Copies of Mediating Medical Negligence Claims: An Option for the Future? by Linda Mulcahy with Marie Selwood, Lee Summerfield and Ann Netten, ISBN 011322268 8, are available from Stationery Office bookshops or by calling 08706005522 .

\title{
Amicus Curiae \\ Submission of articles
}

Readers of Amicus Curiae are welcome to submit contributions (not exceeding 3000 words) for publication. Information, including author style notes, is available on the Internet at: http://ials.sas.ac.uk/amicus.htm

\author{
Please contact Julian Harris for further information at: \\ Institute of Advanced Legal Studies \\ 17 Russell Square, London WC1B 5DR \\ E-mail:julian.harris@sas.ac.uk
}

